\title{
A comparative study on the outcome of mattress sutures and subcuticular sutures in caesarean and hysterectomy in obese patients
}

\section{Padmavathi Narahari, Anilasre Atluri*}

\author{
Department of Obstetrics and Gynecology, Saveetha Medical College and Hospital, Thandalam, Chennai, Tamil Nadu, \\ India
}

Received: 09 October 2020

Revised: 08 February 2021

Accepted: 10 February 2021

\section{*Correspondence:}

Dr. Anilasre Atluri,

E-mail: dranila97@gmail.com

Copyright: ( $)$ the author(s), publisher and licensee Medip Academy. This is an open-access article distributed under the terms of the Creative Commons Attribution Non-Commercial License, which permits unrestricted non-commercial use, distribution, and reproduction in any medium, provided the original work is properly cited.

\begin{abstract}
Background: Selection of method of suturing is very important for a surgeon as it should be cosmetic, less painful, cost-effective and with less post -operative complications. Wound complications are comparatively more in obese than in non-obese patients. This has led to an increase in hospital stay and health cost for the patient. Hence selection of proper suture technique which would result in most favourable outcomes with least complications is of utmost importance. This study aimed to compare the outcome of subcuticular and mattress suture in obese patients.

Methods: This was a retrospective study on 50 obese patients who underwent primary caesarean or hysterectomy with no previous surgeries in the past. Purposive sampling method was used for selection of patients. The wound was assessed by induration, wound discharge, infection, gaping, need for resuturing. All the patients underwent standard post-operative care. Statistical analysis was done by descriptive and inferential statistics.

Results: Among the patients with subcuticular sutures, 15(60\%) had wound induration with severe pain, 10 (40\%) developed wound discharge, $6(24 \%)$ had wound gaping and $6(24 \%)$ required resuturing. Among the group with mattress sutures, 7 (28\%) had wound induration, 3 (12\%) developed wound discharge, 1 (4\%) had wound gaping and required resuturing.

Conclusions: Not only was wound induration and pain higher among the patients with subcuticular skin sutures but these patients had a significant increase in wound gaping and resuturing also when compared to the patients who had undergone closure with mattress skin sutures.
\end{abstract}

Keywords: Caesarean, Hysterectomy, Mattress sutures, Obesity, Subcuticular sutures

\section{INTRODUCTION}

As the existing lifestyle and food habits of people have led to increase in people who are obese, it has also lead to rise in post-operative morbidity and mortality when compared to patients with normal BMI.

Body mass index (BMI) is one of the most objective methods in determining the presence and extent of obesity. ${ }^{1-3}$

As BMI increases to obesity levels, morbidity and mortality rates rise dramatically. ${ }^{4}$ The clinical definition for obesity is a $B M I \geq 30 \mathrm{~kg} / \mathrm{m}^{2}$, with severe obesity defined as a $B M I \geq 35 \mathrm{~kg} / \mathrm{m}^{2}$ and morbid obesity as a $\mathrm{BMI} \geq 40 \mathrm{~kg} / \mathrm{m}^{2}{ }^{5}$ Obesity is responsible for more than 25 percent of the increase in healthcare costs over the past 15 years. $^{4,5}$

From a surgical standpoint, obesity is associated with a multitude of complications including impairments of cutaneous wound healing, total wound failure, and fascial dehiscenc. ${ }^{6}$

As these postsurgical complications often result in unplanned hospital and emergency room visits, as well as 
readmissions, there is an imperative need to improve the outcomes of surgery performed on obese patients in order to help decrease health care costs, healing time, and time away from work.

Our study makes an effort to compare two different types of skin suturing techniques and their impact on wound healing. Subcuticular sutures became very popular among the surgeons in obstetrics and gynecology as they are cosmetically appealing. Our study brings out the problems with this type of suturing in obese patients when compared to traditional mattress sutures. The inherent risk factors of obesity as such has an impact on wound healing and our aim is to understand the differences in the rates of complications among the two suture types so that we chose the best suture depending upon the BMI of the patient in future, thereby reducing the morbidity.

\section{METHODS}

This study was done retrospectively in 50 patients who underwent either an elective caesarean or hysterectomy in Saveetha medical college and hospital between 2017 and 2018. Sampling method was selective purposive sampling method. Among 50, we selected 25 obese patients who had subcuticular skin closure and 25 patients who had mattress skin closure after meeting the inclusion and exclusion criteria.

\section{Inclusion criteria}

Obese patients with suprapubic transverse skin closure using prolene or 1-0 vicryl who underwent primary caesarean or hysterectomy.

\section{Exclusion criteria}

Patients with previous history of surgery, vertical incision, diabetes, anemia, heart disease, HIV positive and any other comorbid conditions were excluded from the study.

Each patient had received pre-operative antibiotic prophylaxis as documented in the records which is a protocol in our hospital.

Post-operative pain associated with induration of wound, wound discharge, wound swab culture reports for infection, need for daily dressing, wound gaping and need for resuturing were assessed in all the patients. Each of these variable was compared in the patients who underwent subcuticular and those who underwent mattress sutures for skin closure. Statistical analysis was done by descriptive and inferential statistics.

\section{RESULTS}

Results of the study were compared using different variables like wound induration, wound discharge, wound gaping and resuturing. All the patients included in the study were of age group 20-55 years.

Table 1: Assessment of wound induration in subcuticular and mattress sutures.

\begin{tabular}{|lll|}
\hline Subcuticular sutures & $\begin{array}{l}\text { Wound } \\
\text { induration }\end{array}$ & $\begin{array}{l}\text { No wound } \\
\text { induration }\end{array}$ \\
\hline Mattress sutures & $15(60 \%)$ & $10(40 \%)$ \\
\hline
\end{tabular}

$\mathrm{p}=0.0226,<0.05$ significant

Among the patients who had subcuticular sutures, 15 developed wound induration whereas in the mattress group 7 developed wound induration. Even at the time of discharge from hospital, these patients had wound induration.

Table 2: Assessment of wound discharge in subcuticular and mattress sutures.

\begin{tabular}{|lll|}
\hline Subcuticular sutures & $\begin{array}{l}\text { Wound } \\
\text { discharge }\end{array}$ & $\begin{array}{l}\text { No wound } \\
\text { discharge }\end{array}$ \\
\hline Mattress sutures & $10(40 \%)$ & $15(60 \%)$ \\
\hline
\end{tabular}

$\mathrm{p}=0.024,<0.05$ significant

Wound discharge was noted in 10 among the 25 patients with subcuticular sutures whereas 3 patients developed discharge in the mattress group. Wound swabs were taken for all the 13 patients with wound discharge and only 2 were found to have growth. They were treated with appropriate sensitive drug.

Table 3: Assessment of wound gaping in subcuticular and mattress sutures.

\begin{tabular}{|c|c|c|}
\hline & $\begin{array}{l}\text { Wound } \\
\text { gaping }\end{array}$ & $\begin{array}{l}\text { No wound } \\
\text { gaping }\end{array}$ \\
\hline Subcuticular sutures & $6(24 \%)$ & $19(76 \%)$ \\
\hline Mattress sutures & $1(4 \%)$ & $24(96 \%)$ \\
\hline
\end{tabular}

$\mathrm{p}=0.0415,<0.05$ significant

Wound gaping was found in 6 among 25 patients in the subcuticular group whereas 1 patient developed so in the mattress group. Wound gaping was noted at the time of suture removal in some patients with wound discharge.

Table 4: Assessment of resuturing in subcuticular and mattress sutures.

\begin{tabular}{|lll|}
\hline & Resuturing & No resuturing \\
\hline Subcuticular sutures & $6(24 \%)$ & $19(76 \%)$ \\
\hline Mattress sutures & $1(4 \%)$ & $24(96 \%)$ \\
\hline
\end{tabular}

Resuturing was done for 6 patients among the subcuticular group and 1 patient in the mattress group. Those patients who developed wound gaping at the time of suture removal either healed spontaneously or needed 
resuturing. This table shows the data of patients who required wound resuturing.

Analysing the above statistics by inferential method, it was clearly evident that the morbidity was more in case of patients with subcuticular sutures in terms of wound induration, gaping and resuturing which was statistically significant when compared to mattress closure.

Data from each variable assessed in the study shows better wound healing with interrupted mattress sutures than with subcuticular sutures in obese patients who were the subjects in this study

\section{DISCUSSION}

Obese patients of any age have excess fat at the wound site that may prevent securing a good closure. In addition, fat does not have a rich blood supply, making it the most vulnerable of all tissues to trauma and infection.

Wound risk factors in obese people are advanced age, hypoxia, infection/sepsis, hyperglycemia, inadequate perfusion, reduced mobility and difficult positional changes.

A number of studies including one by Montz and colleagues have demonstrated that the running mass closure technique using delayed-absorbable or permanent suture placement is just as effective as interrupted. ${ }^{7}$

Some surgeons preference in morbidly obese patients is to place several interrupted sutures to obliterate much of the dead space, facilitate skin closure, and minimise tension on the wound and with this they have noted no significant increase in wound complications. Placement of a closed-suction drain is a good alternative. Whether subcutaneous drain increases the likelihood of wound complications is of irrelevant concern probably as in most cases it is exteriorised via a separate stab wound remote from the incision. ${ }^{8}$

Although laparoscopy has revolutionised the way surgeries are done even for obese patients, in most of the medical colleges residents still have to undergo the traditional training of open surgeries as it is an essential skill and even the teaching faculty are in the learning curve of doing laparoscopic surgeries.

All the above techniques have been employed by various surgeons to facilitate better healing and avoid the anticipated complications in obese women. In this background our study has shown a significant lesser morbidity even with mattress sutures when compared to the subcuticular sutures in obese women operated for caesarean and hysterectomy.

Wang et al showed that there was no difference in postoperative pain. ${ }^{9}$ Subcuticular suture requires more technical expertise, more training, more time, finer surgical skills, finer instruments and costlier suture material but have superior long term cosmetic outcome, better patient compliance and less hospital stay. While mattress suture is easier, needs less training, less time, less surgical skills and cheaper suture material. However, mattress suturing still remains a good choice.

Subcuticular stitches are time consuming and need more expertise than interrupted mattress. Similar were the results of Shwetha et al study. ${ }^{10}$

\section{CONCLUSION}

In conclusion, type of suture should always be decided upon based on the obesity of the patient and not based on gender for cosmetic results. The post-operative complications are higher in obese women inherently due to other factors like DVT, sleep apnoea, delayed recovery etc. and hence we should at least try to minimise the complications related to wound healing. We favour the use mattress in comparison to subcuticular based on our study. Residents in obstetrics and gynecology should be refrained from routine use of subcuticular sutures in all types of patients. However, as this was a retrospective study, more studies may be done on larger populations based on pre-operative BMI in these women prospectively to prove or disprove the same.

\section{ACKNOWLEDGMENTS}

We acknowledge our sincere thanks to the medical records of Saveetha medical college for providing access to the case records.

\section{Funding: No funding sources}

Conflict of interest: None declared

Ethical approval: The study was approved by the Institutional Ethics Committee

\section{REFERENCES}

1. Coutinho W. Latin America consensus on obesity. Arquivos Brasileiros de Endocrinol Metabol. 1999;43:21-67.

2. Pitanguy I, de Amorim NFG, Radwanski HN. Contour surgery in the patient with great weight loss. Aesth Plast Surg. 2000;24(6):406-11.

3. Rosen JC, Orosan P, Reiter J. Cognitive behavior therapy for negative body image in obese women. Behav Therap. 1995;26(1):25-42.

4. Thorpe KE, Florence CS, Howard DH, Joski P. The impact of obesity on rising medical spending. Health Affairs. 2004;(Web Exclusives):480-6.

5. Encinosa WE, Bernard DM, Chen CC, Steiner CA. Healthcare utilization and outcomes after bariatric surgery. Med Care. 2006;44(8):706-12.

6. Pitanguy I, de Amorim NFG, Radwanski HN. Contour surgery in the patient with great weight loss. Aesth Plast Surg. 2000;24(6):406-11. 
7. Montz FJ, Creasman WT, Eddy G, DiSaia PJ. Running mass closure of abdominal wounds using absorbable looped suture. J Gynecol Surg. 1991;7:107-10.

8. Ramsey PS, White AM, Guinn DA, Lu GC, Ramin SM, Davies JK, et al. Subcutaneous tissue reapproximation, alone or in combination with drain, in obese women undergoing caesarean delivery. Obstet Gynecol. 2005;105:967-73.

9. Wang $\mathrm{H}$, Hong $\mathrm{S}$, Teng $\mathrm{H}$, Qiao $\mathrm{L}$, Yin $\mathrm{H}$. Subcuticular sutures versus staples for skin closure after cesarean delivery: a meta-analysis. J Matern Fet Neonat Med. 2016;4:1-32.

10. Shwetha BR, Nair RV, Pillai JT, Prashant VS. Comparison between interrupted vertical mattress versus subcuticular suture for skin closure in caesarean section at SMIMS. IJRR. 2016;3:33-6.

Cite this article as: Narahari $\mathrm{P}$, Atluri A. A comparative study on the outcome of mattress sutures and subcuticular sutures in caesarean and hysterectomy in obese patients. Int J Reprod Contracept Obstet Gynecol 2021;10:935-8. 